\title{
Transfer of Peptococcus indolicus, Peptococcus asaccharolyticus, Peptococcus prevotii, and Peptococcus magnus to the Genus Peptostreptococcus and Proposal of Peptostreptococcus tetradius sp. nov.
}

\author{
TAKAYUKI EZAKI, ${ }^{1 *}$ NAOKI YAMAMOTO,${ }^{1}$ KEIU NINOMIYA,${ }^{2}$ SHOICHIRO SUZUKI,${ }^{3}$ AND EIKO \\ YABUUCHI ${ }^{1}$
}

Department of Microbiology, Gifu University School of Medicine, 40 Tsukasa-machi, Gifu, 500, Japan ${ }^{1}$; Obstetrics and Gynecology Department, Tajimi Municipal Hospital, Maehata-cho, Tajimi, 507, Japan ${ }^{2}$; and International Academy of Paramedical Technology, Nagamine 795, Ichi-hiraga, Seki, 506, Japan ${ }^{3}$

The guanine-plus-cytosine $(\mathrm{G}+\mathrm{C})$ contents of the deoxyribonucleic acids (DNAs) of Peptococcus asaccharolyticus ATCC $14963^{\mathrm{T}}$ (T = type strain), Peptococcus indolicus ATCC $29427^{\mathrm{T}}$, Peptococcus prevotii ATCC $9321^{\mathrm{T}}$, and Peptococcus magnus ATCC $15794^{\mathrm{T}}$ ranged from 29 to $34 \mathrm{~mol} \%$, whereas the $\mathrm{G}+\mathrm{C}$ content of the DNA of Peptococcus niger ATCC $27731^{\mathrm{T}}$, the type species of the genus Peptococcus, is $51 \mathrm{~mol} \%$. The $\mathrm{G}+\mathrm{C}$ content of the DNA of Peptostreptococcus anaerobius ATCC $27337^{\mathrm{T}}$, the type species of the genus Peptostreptococcus, was 33 mol\%. Thus, the DNA base compositions of Peptococcus asaccharolyticus, Peptococcus indolicus, Peptococcus prevotii, and Peptococcus magnus resemble the DNA base composition of the type species of the genus Peptostreptococcus rather than the DNA base composition of the type species of the genus Peptococcus. It is not desirable for the genus Peptococcus to include any species whose $\mathrm{G}+\mathrm{C}$ content is far from the $\mathrm{G}+\mathrm{C}$ content of the type species of the genus. The levels of DNA-DNA homology between Peptostreptococcus anaerobius ATCC $27337^{\mathrm{T}}$ and the four species of Peptococcus with low $\mathrm{G}+\mathrm{C}$ DNA contents ranged from 23 to $36 \%$. The cellular fatty acid profiles of Peptococcus asaccharolyticus, Peptococcus indolicus, Peptococcus prevotii, and Peptococcus magnus also resembled the cellular fatty acid profile of the type species of Peptostreptococcus. Other biochemical characteristics of these species revealed their close resemblance to Peptostreptococcus anaerobius. For these reasons we propose transfer of the four Peptococcus species that have low $\mathrm{G}+\mathrm{C}$ contents to the genus Peptostreptococcus as Peptostreptococcus asaccharolyticus (Distaso 1912) comb. nov., Peptostreptococcus indolicus (Christiansen 1934) comb. nov., Peptostreptococcus prevotii (Foubert and Douglas 1948) comb. nov., and Peptostreptococcus mangus (Prévot 1933) Smith 1957 comb. rev. A group of organisms previously referred to as "Gaffkya anaerobia" (Choukévitch) Prévot is an identifiable Peptostreptococcus species based on phenotypic and genotypic characteristics. The name of Peptostreptococcus tetradius sp. nov. is proposed for this group of organisms. Strain GIFU $7672(=$ ATCC 35098) is designated the type strain. Clinical strains of $P$. asaccharolyticus that were identified by conventional methods were divided into two homology groups and one unclassified group (A-1). DNA-DNA homology between the type strain of $P$. prevotii and clinical strains which had been received as $P$. prevotii ranged from 0 to $73 \%$.

When this work was initiated, the genus Peptococcus Kluyver and van Niel 1936 was composed of seven species, including the type species, Peptococcus niger. The genus Peptostreptococcus Kluyver and van Niel 1936 contained four species, with Peptostreptococcus anaerobius as the type species. Peptococcus and Peptostreptococcus, together with Coprococcus, Ruminococcus, and Sarcina, are members of the family Peptococcaceae. These gen- era have been separated from each other by cellular arrangement, metabolic end products, and utilization of peptides and carbohydrates $(15,31,32)$. However, reliable characteristics for differentiating Peptococcus and Peptostreptococcus have not been proposed. We recently reported that the guanine-plus-cytosine $(\mathrm{G}+\mathrm{C})$ contents of the deoxyribonucleic acids (DNAs) of the type strains of Peptococcus asaccharolyticus, Peptococcus indolicus, Peptococcus pre- 
votii, Peptococcus magnus, and Staphylococcus saccharolyticus (Peptococcus saccharolyticus) are very different from the $\mathrm{G}+\mathrm{C}$ content of Peptococcus niger DNA, whereas these values are similar to the value for Peptostreptococcus anaerobius DNA (14). The $\mathrm{G}+\mathrm{C}$ contents of strains with characteristics similar to those described for "Gaffkya anaerobia" also are similar to the $\mathrm{G}+\mathrm{C}$ content of Peptostreptococcus anaerobius.

This study of the genera Peptococcus and Peptostreptococcus was based on extensive biochemical characterization of 262 strains of grampositive anaerobic cocci, chiefly of clinical origin, and the $\mathrm{G}+\mathrm{C}$ contents and levels of DNADNA homology among selected strains. The taxonomic position of "G. anaerobia" also was determined.

\section{MATERIALS AND METHODS}

Bacterial strains. From about 300 strains of anaerobic gram-positive cocci isolated mostly from human clinical specimens, 65 were selected for this study (Table 1). These 65 strains, which were stored in $10 \%$ skim milk at $-90^{\circ} \mathrm{C}$, were transferred into Gifu anaerobic medium (GAM; Nissui, Tokyo, Japan) broth and then streaked onto GAM plates for discrete colony formation. Cultures were incubated anaerobically for $48 \mathrm{~h}$ at $37^{\circ} \mathrm{C}$. Working cultures were maintained in GAM broth.

Bacterial identification. All media were prepared anaerobically, kept for $48 \mathrm{~h}$ in an anaerobic chamber ( $85 \%$ nitrogen, $5 \%$ hydrogen, $10 \%$ carbon dioxide) before use, and inoculated under carbon dioxide gas. Carbohydrate fermentation tests and other biochemical tests were performed by the methods described in the Anaerobe Laboratory Manual, 4th ed. (14).

For volatile and nonvolatile fatty acid analyses, each strain was grown both in prereduced peptoneyeast extract medium supplemented with $1 \%$ glucose (PYG medium) and in GAM medium supplemented with $1 \%$ glucose for 1 week at $37^{\circ} \mathrm{C}$. For gas-liquid chromatographic analyses, cultures were processed according to the methods described in the Anaerobe Laboratory VPI Manual, 4th ed. (14). A Shimadzu model GC-6A gas chromatograph equipped with a flame ionization detector was used. Peptone-yeast extract broth was the basal medium used for the biochemical tests.

Ammonia production from amino acids. A filtersterilized $10 \%(\mathrm{wt} / \mathrm{vol})$ aqueous amino acid solution was added to peptone-yeast extract broth to make a final concentration of $0.7 \%$. After anaerobic incubation for 1 week, 2 drops of the culture and 4 drops of Nessler solution were placed onto a spot plate. Peptone-yeast extract broth cultures were tested simultaneously as controls. A stronger orange color with the amino acid culture than with the peptone-yeast extract broth culture was considered a positive reaction.

API ZYM tests. Bacterial strains cultured in $20 \mathrm{ml}$ of prereduced GAM broth for 2 days at $37^{\circ} \mathrm{C}$ were centrifuged, and the sedimented cells were washed once with saline. After recentrifugation, a saline suspension of each strain was prepared to equal the turbidity of a MacFarland no. 5 standard. Enzyme activities were determined after $4 \mathrm{~h}$ of incubation at $37^{\circ} \mathrm{C}$. Activity scores of 3 to 5 were considered positive, and a score of 2 was considered weakly positive.

Analysis of cellular fatty acids. The cells of 23 strains (see Table 4) grown anaerobically in GAM broth for 24 to $36 \mathrm{~h}$ were sedimented by centrifugation and washed twice with distilled water. After whole-cell saponification, the cellular fatty acids were methylated and extracted by the procedure of Moss and Dees (29). The fatty acid methyl esters were analyzed with a gas chromatograph equipped with a fused silica capillary column ( $25 \mathrm{~m}$ by $0.2 \mathrm{~mm}$ [inner diameter]) coated with 3\% OV-101 (Shimadzu, Kyoto, Japan). The temperature of the column was programmed to increase from 150 to $250^{\circ} \mathrm{C}$ at a rate of $5^{\circ} \mathrm{C} / \mathrm{min}$ after sample injection. The fatty acid methyl esters were identified by comparing their retention times with those of fatty acid methyl ester standards. Identification was further confirmed by analysis on a polar column (Diacot EW FFAP; $20 \mathrm{~m}$ by $0.28 \mathrm{~cm}$ [inner diameter]; Japan Chromatography, Tokyo, Japan) and by gas-liquid chromatography-mass spectrometry (29).

DNA isolation. Each of the 65 selected strains (see Table 2) was incubated anaerobically in 1.8 liter of GAM broth at $37^{\circ} \mathrm{C}$ for $36 \mathrm{~h}$. The bacterial cells were sedimented by centrifugation and then suspended in a solution containing $0.15 \mathrm{M} \mathrm{NaCl}$ and $0.01 \mathrm{M}$ ethylenediaminetetraacetic acid ( $\mathrm{pH} \mathrm{8.0)}$. Achromopeptidase (Wako Chemical, Osaka, Japan) and lysozyme (Sigma Chemical Co., St. Louis, Mo.) were each added to a final concentration of $2,000 \mathrm{U} / \mathrm{ml}$. The suspension was kept at $35^{\circ} \mathrm{C}$ until the solution became clear. The organisms resistant to the lytic activity of achromopeptidase and lysozyme were disrupted by shaking with beads (B. Braun, Melsungen, West Germany). After the cells were lysed, sodium dodecyl sulfate (final concentration, $1 \%$ ) was added, and the solution was held at $60^{\circ} \mathrm{C}$ for $10 \mathrm{~min}$, after which pronase $\mathrm{E}$ (Kaken Chemical, Tokyo, Japan) was added to the solution to a final concentration of $100 \mu \mathrm{g} / \mathrm{ml}$. The viscosity of the lysate was reduced by sonication (Tomy Seiko, Tokyo, Japan) at a $70 \%$ energy setting. Ribonuclease I from bovine pancreas (Miles Laboratories Inc., Elkhart, Ind.) was added to the lysate to a final concentration of a $100 \mu \mathrm{g} / \mathrm{ml}$, and then the lysate was incubated for $1 \mathrm{~h}$ at $35^{\circ} \mathrm{C}$. After preliminary extraction with chromatography-grade phenol in $\mathbf{0 . 1 5}$ $\mathrm{M} \mathrm{NaCl}-0.01 \mathrm{M}$ ethylenediaminetetraacetic acid $(\mathrm{pH}$ 8.0), the DNA was extracted by the method of Marmur (28).

Determination of the $G+C$ content of the DNA. The thermal melting point of DNA was measured with an automatic recording spectrophotometer (Japan Spectroscopic, Tokyo, Japan) equipped with four sampling chambers and a cell programmer, as described previously (9). Reference DNA from Escherichia coli strain $\mathrm{K}-12$ was used for each experimental run. The $\mathrm{G}+\mathrm{C}$ value was calculated by the equation of Mandel et al. (27). To maintain comparable conditions, the DNAs of strain K-12 and 72 strains of anaerobic cocci were dialyzed in the same $0.5 \mathrm{M}$ saline-trisodium citrate buffer ( $\mathrm{pH} \mathrm{7.0)}$ before each experimental run.

DNA-DNA homology experiments. The DNA-DNA homology procedures used have been described previously (9). DNA was labeled with $\left[{ }^{3} \mathrm{H}\right]$ thymidine triphosphate by a nick-translation method (20). After labeling, the reaction mixture was passed through a 
column ( 1 by $7.5 \mathrm{~cm}$ ) of 100 - to 200 -mesh Bio-Gel P100 polyacrylamide (Bio-Rad Laboratories, Richmond, Calif.), using $0.1 \times$ saline-trisodium citrate buffer $(\mathrm{pH}$ 7.0 ) containing $0.1 \%$ sodium dodecyl sulfate. The specific activity of the labeled DNA preparation was about $3 \times 10^{5}$ to $2 \times 10^{6} \mathrm{cpm} / \mu \mathrm{g}$. Membrane homology experiments were performed by the procedure of Gillespie and Spiegelman (12), with minor modifications (9). Reassociation reactions were run in $2 \times$ saline-trisodium citrate buffer $\left(\mathrm{pH} \mathrm{7.0)}\right.$ at $55^{\circ} \mathrm{C}$ for $24 \mathrm{~h}$.

\section{RESULTS AND DISCUSSION}

Evidence for the transfer of four species of Peptococcus to the genus Peptostreptococcus. (i) $G+C$ contents of DNAs and DNA-DNA homology values. The $G+C$ contents of DNAs from the type strains of Peptococcus asaccharolyticus, Peptococcus indolicus, Peptococcus prevotii, and Peptococcus magnus ranged from 32 to 34 mol\%, values close to the value of $33 \mathrm{~mol} \%$ obtained for the DNA of the type strain of Peptostreptococcus anaerobius and far from the value of 50 to $51 \mathrm{~mol} \%$ obtained for the DNA of the type strain of Peptococcus niger (38) (Table 2). The levels of DNA-DNA homology between the type strain of Peptostreptococcus anaerobius and the type strains of Peptococcus asaccharolyticus, Peptococcus indolicus, Peptococcus prevotii, and Peptococcus magnus ranged from 23 to $36 \%$, whereas negligible homology ( 0 to $6 \%$ ) was observed between these strains and the type strain of Peptococcus niger. These values indicate that Peptococcus asaccharolyticus, Peptococcus indolicus, Peptococcus prevotii, and Peptococcus magnus are more closely related to Peptostreptococcus anaerobius, the type species of the genus Peptostreptococcus, than to Peptococcus niger, the type species of the genus Peptococcus. Therefore, we propose that these organisms be transferred to the genus Peptostreptococcus as Peptostreptococcus asaccharolyticus (Distaso) comb. nov., Peptostreptococcus indolicus (Christiansen) comb. nov., Peptostreptococcus prevotii (Foubert and Douglas) comb. nov., and Peptostreptococcus magnus (Prévot) Smith 1957 comb. rev.

(ii) Morphological and biochemical characters. Present descriptions of the family Peptococcaceae do not allow separation of the genus Peptococcus from the genus Peptostreptococcus. Chain formation has been cited as a major factor to discriminate between these two genera (15, 32 ), but this is not always a reliable character. In strains of Peptostreptococcus anaerobius, chains usually are present in stained preparations of cultures grown in broth medium, but not in stained preparations made from growth on solid medium. Moreover, strains of species of Peptococcus occasionally form chains. Catalase production, which is useful in differentiating staphylococci from streptococci, cannot be used to differentiate peptococci from peptostreptococci because catalase production varies among species, or even among strains of a species, in these genera.

Peptococcus niger does not ferment carbohydrates. Strains of Peptostreptococcus anaerobius are weakly saccharolytic, as are strains of Peptococcus prevotii and some strains of Peptococcus magnus (Table 3). However, carbohydrates are not fermented by strains of Peptococcus indolicus and by most strains of Peptococcus asaccharolyticus. Even though we have found no usual phenotypic test or morphological characteristic that can differentiate between Peptococcus and Peptostreptococcus, the validity of separate genera is established by the differences in the $G+C$ contents of the DNAs of the type species of the two genera, and the proposed transfer of the four species to Peptostreptococcus is supported by the $\mathrm{G}+\mathrm{C}$ contents of the species and our DNA-DNA homology results.

(iii) Cellular fatty acid profiles. The cellular fatty acid profiles of GAM cultures of the butyric acid-producing species of Peptococcus resembled the profile of the type strain of Peptostreptococcus anaerobius (Table 4). The profiles of these cocci incubated in PYG broth were different from the profiles of cultures incubated in GAM broth (data not shown). Differences in medium composition also may account for slight differences between our results and previous results (25). C18:1 was a major cellular fatty acid in cultures in both PYG and GAM. C18:1 aldehyde was detected in most cultures. Therefore, the cellular fatty acid profiles support the inclusion of Peptococcus asaccharolyticus, Peptococcus indolicus, Peptococcus prevotii, and Peptococcus magnus in the genus Peptostreptococcus.

Emended description of the genus Peptostreptococcus. (i) History and discussion. Kluyver and van Niel (24) first named the genera Peptococcus and Peptostreptococcus and assigned them to the families Micrococcaceae and Streptococcaceae, respectively. Rogosa placed these genera in a new family, the Peptococcaceae (32).

Of the seven species of Peptococcus on the Approved Lists of Bacterial Names (36), only Peptococcus niger will remain after transfer of Peptococcus asaccharolyticus, Peptococcus indolicus, Peptococcus magnus, and Peptococcus prevotii to the genus Peptostreptococcus. On the basis of nucleic acid studies $(7,21,22)$, cell wall analyses (35), and biochemical studies (35), Kilpper-Bälz and Schleifer (23) proposed the transfer of Peptococcus saccharolyticus to the genus Staphylococcus. We found that the cellular fatty acids of Staphylococcus saccharolyticus were different from the cellular fatty acids of 
TABLE 1. Origins of the 65 selected strains

\begin{tabular}{|c|c|c|c|c|c|}
\hline Species or group & $\begin{array}{l}\text { GIFU } \\
\text { strain } \\
\text { no. }\end{array}$ & Received as: & $\begin{array}{c}\text { Other strain } \\
\text { no. }\end{array}$ & Source of isolation & $\begin{array}{l}\text { Received } \\
\text { from: }\end{array}$ \\
\hline $\begin{array}{l}\text { Peptostreptococcus } \\
\text { anaerobius }\end{array}$ & 7882 & $\begin{array}{l}\text { Peptostreptococcus } \\
\text { anaerobius }\end{array}$ & ATCC $27337^{\mathrm{T}}$ & Not recorded & 7 \\
\hline \multirow[t]{15}{*}{$\begin{array}{l}\text { Peptostreptococcus } \\
\text { asaccharolyticus }\end{array}$} & 7656 & $\begin{array}{l}\text { Peptococcus } \\
\text { asaccharolyticus }\end{array}$ & ATCC $14963^{\mathrm{T}}$ & Not recorded & 7 \\
\hline & 3302 & $\begin{array}{l}\text { Peptococcus } \\
\text { asaccharolyticus }\end{array}$ & & Skin abscess & 3 \\
\hline & 7877 & $\begin{array}{l}\text { Peptococcus } \\
\text { asaccharolyticus }\end{array}$ & & Vaginal discharge & 2 \\
\hline & 3306 & $\begin{array}{l}\text { Peptococcus } \\
\quad \text { asaccharolyticus }\end{array}$ & & Vaginal discharge & 4 \\
\hline & 6287 & $\begin{array}{l}\text { Peptococcus } \\
\quad \text { asaccharolyticus }\end{array}$ & & Vaginal discharge & 4 \\
\hline & 3315 & $\begin{array}{l}\text { Peptococcus } \\
\quad \text { asaccharolyticus }\end{array}$ & & Vaginal discharge & 3 \\
\hline & 3290 & $\begin{array}{l}\text { Peptococcus } \\
\text { asaccharolyticus }\end{array}$ & & Peritoneal abscess & 3 \\
\hline & 7951 & $\begin{array}{l}\text { Peptococcus } \\
\text { asaccharolyticus }\end{array}$ & & Vaginal discharge & 4 \\
\hline & 6663 & $\begin{array}{l}\text { Peptococcus } \\
\text { asaccharolyticus }\end{array}$ & & Otorrhea & 3 \\
\hline & 6291 & $\begin{array}{l}\text { Peptococcus } \\
\text { asaccharolyticus }\end{array}$ & & Skin abscess & 4 \\
\hline & 7871 & $\begin{array}{l}\text { Peptococcus } \\
\text { asaccharolyticus }\end{array}$ & & Vaginal discharge & 2 \\
\hline & 7693 & $\begin{array}{l}\text { Peptococcus } \\
\text { asaccharolyticus }\end{array}$ & & Vaginal discharge & 3 \\
\hline & 7681 & $\begin{array}{l}\text { Peptococcus } \\
\text { asaccharolyticus }\end{array}$ & & Vaginal discharge & 3 \\
\hline & 7939 & $\begin{array}{l}\text { Peptococcus } \\
\text { asaccharolyticus }\end{array}$ & & Vaginal discharge & 4 \\
\hline & 7955 & $\begin{array}{l}\text { Peptococcus } \\
\quad \text { asaccharolyticus }\end{array}$ & & Vaginal discharge & 2 \\
\hline \multirow[t]{3}{*}{ Unclassified group A-1 } & 1244 & $\begin{array}{l}\text { Peptococcus } \\
\text { asaccharolyticus }\end{array}$ & & Feces & 4 \\
\hline & 7662 & $\begin{array}{l}\text { Peptococcus } \\
\text { asaccharolyticus }\end{array}$ & & Feces & 4 \\
\hline & 7872 & $\begin{array}{l}\text { Peptococcus } \\
\text { asaccharolyticus }\end{array}$ & & Vaginal discharge & 5 \\
\hline \multirow[t]{4}{*}{$\begin{array}{l}\text { Peptostreptococcus } \\
\text { indolicus }\end{array}$} & 7848 & $\begin{array}{l}\text { Peptococcus } \\
\text { indolicus }\end{array}$ & ATCC $29427^{\mathrm{T}}$ & $\begin{array}{l}\text { Summer mastitis } \\
\text { secretion of heifer }\end{array}$ & 7 \\
\hline & 8287 & $\begin{array}{l}\text { Peptococcus } \\
\text { indolicus }\end{array}$ & 172 PcR8 & Not recorded & 6 \\
\hline & 8288 & $\begin{array}{l}\text { Peptococcus } \\
\text { indolicus }\end{array}$ & 196 PcR3 & Not recorded & 6 \\
\hline & 8296 & $\begin{array}{l}\text { Peptococcus } \\
\text { indolicus }\end{array}$ & & Rat feces & 4 \\
\hline \multirow[t]{7}{*}{ Peptostreptococcus prevotii } & 7658 & Peptococcus prevotii & ATCC $9321^{1}$ & Plasma & 7 \\
\hline & 7789 & Peptococcus prevotii & & Vaginal discharge & 4 \\
\hline & 7732 & Peptococcus prevotii & & Skin abscess & 3 \\
\hline & 7794 & Peptococcus prevotii & & Vaginal discharge & 4 \\
\hline & 7678 & Peptococcus prevotii & & $\begin{array}{l}\text { Discharge from } \\
\text { peritonitis }\end{array}$ & 3 \\
\hline & 7695 & Peptococcus prevotii & & Vaginal discharge & 3 \\
\hline & 7954 & Peptococcus prevotii & & Ovarial abscess & 2 \\
\hline \multirow{5}{*}{$\begin{array}{l}\text { Peptostreptococcus } \\
\text { tetradius }\end{array}$} & $7672^{\mathrm{T}}$ & "Gaffkya anaerobia", & & Vaginal discharge & 4 \\
\hline & 3282 & "Gaffkya anaerobia'" & & Otorrhea & 3 \\
\hline & 3298 & "Gaffkya anaerobia", & & Vaginal discharge & 2 \\
\hline & 3270 & "Gaffkya anaerobia", & & Vaginal discharge & 3 \\
\hline & 7617 & "Gaffkya anaerobia" & & Vaginal discharge & 4 \\
\hline \multirow[t]{2}{*}{ Unclassified group P-1 } & 7668 & Peptococcus prevotii & & Lacrimal sac & 1 \\
\hline & 7878 & Peptococcus prevotii & & $\begin{array}{c}\text { Discharge from } \\
\text { endometritis }\end{array}$ & 3 \\
\hline
\end{tabular}


TABLE 1-Continued

\begin{tabular}{|c|c|c|c|c|c|}
\hline Species or group & $\begin{array}{l}\text { GIFU } \\
\text { strain } \\
\text { no. }\end{array}$ & Received as: & $\begin{array}{l}\text { Other strain } \\
\text { no. }\end{array}$ & Source of isolation & $\begin{array}{l}\text { Received } \\
\text { from: }^{a}\end{array}$ \\
\hline \multirow{23}{*}{$\begin{array}{l}\text { Peptostreptococcus } \\
\text { magnus }\end{array}$} & 7629 & Peptococcus magnus & ATCC $15794^{\mathrm{T}}$ & Not recorded & 7 \\
\hline & 7726 & Peptococcus magnus & & Vaginal discharge & 3 \\
\hline & 7795 & Peptococcus magnus & & Vaginal discharge & 2 \\
\hline & 7943 & Peptococcus magnus & & Vaginal discharge & 2 \\
\hline & 7711 & Peptococcus magnus & & $\begin{array}{l}\text { Discharge from } \\
\text { endometritis }\end{array}$ & 3 \\
\hline & 7724 & Peptococcus magnus & & Otorrhea & 3 \\
\hline & 7624 & Peptococcus magnus & & Vaginal discharge & 3 \\
\hline & 7785 & Peptococcus magnus & & Vaginal discharge & 4 \\
\hline & 7655 & Peptococcus magnus & & Vaginal discharge & 3 \\
\hline & 7651 & Peptococcus magnus & & Skin abscess & 3 \\
\hline & 7735 & Peptococcus magnus & & Skin abscess & 5 \\
\hline & 7792 & Peptococcus magnus & & Vaginal discharge & 4 \\
\hline & 7661 & Peptococcus magnus & & Lung abscess & 4 \\
\hline & 7723 & Peptococcus magnus & & Ovarial abscess & 3 \\
\hline & 7677 & Peptococcus magnus & & Skin abscess & 3 \\
\hline & 7957 & Peptococcus magnus & & Vaginal discharge & 4 \\
\hline & 7881 & Peptococcus magnus & ATCC 14955 & Draining sinus & 7 \\
\hline & 7700 & Peptococcus magnus & & Vaginal discharge & 4 \\
\hline & 7716 & Peptococcus magnus & & Skin abscess & 2 \\
\hline & 7654 & Peptococcus magnus & & Ovarial abscess & 4 \\
\hline & 7690 & Peptococcus magnus & & Blood culture & 4 \\
\hline & 7644 & Peptococcus magnus & & Skin abscess & 3 \\
\hline & 7679 & Peptococcus magnus & & Vaginal discharge & 3 \\
\hline Peptostreptococcus micros & 7824 & $\begin{array}{l}\text { Peptostreptococcus } \\
\text { micros }\end{array}$ & VPI $5464^{\mathrm{T}}$ & Prulent pleuresy & 8 \\
\hline $\begin{array}{l}\text { Peptostreptococcus } \\
\quad \text { productus }\end{array}$ & 7707 & $\begin{array}{l}\text { Peptostreptococcus } \\
\quad \text { productus }\end{array}$ & ATCC $27340^{\mathrm{T}}$ & Septicemia & 7 \\
\hline $\begin{array}{l}\text { Staphylococcus } \\
\text { saccharolyticus }\end{array}$ & 7633 & $\begin{array}{l}\text { Peptococcus } \\
\text { saccharolyticus }\end{array}$ & ATCC $14953^{\mathrm{T}}$ & Plasma & 7 \\
\hline Streptococcus parvulus & 7866 & $\begin{array}{l}\text { Peptostreptococcus } \\
\text { parvulus }\end{array}$ & VPI $0546^{\mathrm{T}}$ & Not recorded & 8 \\
\hline Peptococcus niger & 7850 & Peptococcus niger & ATCC $27731^{\mathrm{T}}$ & Umbilicus & 7 \\
\hline
\end{tabular}

${ }^{a}$ Sources: 1, Niigata University Hospital, Niigata, Japan; 2, Tajimi Municipal Hospital, Tajimi, Japan; 3, Jundendo University Hospital, Tokyo, Japan; 4, Gifu University, Gifu, Japan; 5, Nagoya City Hospital, Nagoya, Japan; 6, Swedish University of Agricultural Science, Uppsala, Sweden; 7, American Type Culture Collection, Rockville, Md.; 8, Virginia Polytechnic Institute and State University, Blacksburg, Va.

species of peptostreptococci (Table 4), and strains of Staphylococcus saccharolyticus were sensitive to both lysozyme and achromopeptidase (11).

Cato et al. (4) have shown that Peptococcus glycinophilis (2) is a later synonym of Peptostreptococcus micros. The DNAs of the type strains of these two species show $84 \%$ homology (4).

(ii) Peptostreptococcus Kluyver and van Niel 1980. Cells are spherical to ovoid and 0.3 to 1.8 $\mu \mathrm{m}$ in diameter and occur in pairs, masses, tetrads, or chains. Gram-positive. Strictly anaerobic. Usually nonhemolytic on sheep or rabbit blood agar. A few strains are hemolytic. Colonies are pinpoint to $2 \mathrm{~mm}$ in diameter, circular, smooth, and translucent. Peptone and amino acids can be used as major energy sources. Metabolic end products from PYG broth vary among species. Acidic products may include any of the following: acetic, butyric, isocaproic, lactic, propionic, isobutyric, and isovaleric acids. Catalase variable. Gas production in peptone-yeast extract and peptone-yeast extractglucose media is variable. The saccharolytic activity of most species is negative or only weakly positive. Tween 80 enhances fermentation of carbohydrates by some species.

Isolated from female genital tracts, feces, blood, and abscesses of various sites.

The $\mathrm{G}+\mathrm{C}$ content of the DNA ranges from 28 to $34 \mathrm{~mol} \%$, as determined by thermal denaturation $\left(T_{m}\right)$, except for Peptostreptococcus productus, whose $\mathrm{G}+\mathrm{C}$ content is $45 \mathrm{~mol} \%\left(T_{m}\right)$.

The type species is Peptostreptococcus anaerobius (Natvig 1905) Kluyver and van Niel 1936.

In addition, the saccharolytic species Peptostreptococcus parvulus and Peptostreptococcus productus have DNAs with $\mathrm{G}+\mathrm{C}$ contents 
TABLE 2. DNA-DNA homologies among the 65 selected strains of anaerobic cocci

\begin{tabular}{|c|c|c|c|c|c|c|c|c|c|}
\hline \multirow{3}{*}{ Competitive DNA from: } & \multirow{3}{*}{$\begin{array}{c}\mathrm{G}+\mathrm{C} \\
\text { content } \\
\text { (mol\%) }\end{array}$} & \multicolumn{8}{|c|}{$\%$ Homology with labeled DNA from: } \\
\hline & & \multicolumn{2}{|c|}{$\begin{array}{l}\text { Peptostrepto- } \\
\text { coccus asaccha- } \\
\text { rolyticus }\end{array}$} & \multirow{2}{*}{$\begin{array}{c}\text { Unclassified } \\
\text { group A-1 } \\
\text { strain GIFU } \\
1244\end{array}$} & \multirow{2}{*}{$\begin{array}{c}\text { Peptostrepto- } \\
\text { coccus } \\
\text { prevotii } \\
\text { ATCC } 9321^{\mathrm{T}}\end{array}$} & \multirow{2}{*}{$\begin{array}{c}\text { Peptostrepto- } \\
\text { coccus } \\
\text { tetradius } \\
\text { GIFU } 7672^{\mathrm{T}}\end{array}$} & \multicolumn{2}{|c|}{$\begin{array}{l}\text { Peptostrepto- } \\
\text { coccus magnus }\end{array}$} & \multirow{2}{*}{$\begin{array}{c}\text { Peptostrepto- } \\
\text { coccus } \\
\text { anaerobius } \\
\text { ATCC } 27337^{\mathrm{T}}\end{array}$} \\
\hline & & $\begin{array}{l}\text { ATCC } \\
14963^{\mathrm{T}}\end{array}$ & $\begin{array}{c}\text { GIFU } \\
6663\end{array}$ & & & & $\begin{array}{l}\text { ATCC } \\
15794^{\mathrm{T}}\end{array}$ & $\begin{array}{l}\text { ATCC } \\
14955\end{array}$ & \\
\hline \multicolumn{10}{|l|}{ Peptostreptococcus anaerobius } \\
\hline ATCC $27337^{\mathrm{T}}$ & 33 & 26 & $\mathrm{NT}^{a}$ & NT & 25 & 20 & NT & 23 & 100 \\
\hline \multicolumn{10}{|c|}{$\begin{array}{l}\text { Peptostreptococcus asaccharolyticus } \\
\text { homology group } 1\end{array}$} \\
\hline ATCC $14963^{\mathrm{T}}$ & 32 & 100 & 58 & 56 & 35 & 23 & NT & NT & 25 \\
\hline GIFU 3302 & 33 & 107 & NT & NT & 30 & NT & NT & NT & 31 \\
\hline GIFU 7877 & 33 & 102 & NT & NT & 23 & NT & NT & NT & NT \\
\hline GIFU 3306 & 33 & 101 & 46 & NT & 28 & NT & NT & NT & NT \\
\hline GIFU 6287 & 34 & 100 & NT & NT & 22 & NT & NT & NT & NT \\
\hline GIFU 3315 & 32 & 99 & NT & NT & 23 & NT & NT & NT & NT \\
\hline GIFU 3290 & 33 & 97 & NT & NT & 23 & NT & NT & NT & NT \\
\hline GIFU 7951 & 33 & 97 & NT & NT & 20 & NT & NT & NT & NT \\
\hline \multicolumn{10}{|c|}{ Peptostreptococcus asaccharolyticus } \\
\hline GIFU 6663 & 33 & 52 & 100 & NT & 14 & NT & NT & NT & NT \\
\hline GIFU 6291 & 34 & 58 & 103 & 28 & 27 & NT & NT & NT & NT \\
\hline GIFU 7871 & 32 & 34 & 96 & NT & 27 & NT & NT & NT & NT \\
\hline GIFU 7693 & 34 & 40 & 89 & NT & 27 & NT & NT & NT & NT \\
\hline GIFU 7681 & 34 & 67 & 75 & NT & 30 & 29 & NT & NT & 34 \\
\hline GIFU 7939 & 34 & 32 & 71 & NT & 21 & NT & NT & NT & NT \\
\hline GIFU 7955 & 33 & 53 & 65 & NT & 27 & NT & NT & NT & NT \\
\hline \multicolumn{10}{|l|}{ Unclassified group A-1 } \\
\hline GIFU 1244 & 30 & 48 & 22 & 100 & 44 & NT & NT & NT & NT \\
\hline GIFU 7662 & 31 & 47 & 24 & 90 & 32 & NT & NT & NT & NT \\
\hline GIFU 7872 & 31 & 33 & 25 & 76 & 34 & NT & NT & NT & NT \\
\hline \multicolumn{10}{|l|}{ Peptostreptococcus indolicus } \\
\hline ATCC $29427^{\mathrm{T}}$ & 34 & 15 & NT & NT & 20 & NT & NT & NT & NT \\
\hline GIFU 8287 & 33 & 34 & NT & NT & 33 & NT & NT & NT & 27 \\
\hline GIFU 8288 & 33 & 27 & NT & NT & 22 & NT & NT & NT & 31 \\
\hline GIFU 8296 & 33 & 23 & NT & NT & 37 & NT & NT & NT & NT \\
\hline \multicolumn{10}{|l|}{ Peptostreptococcus prevotii } \\
\hline ATCC $9321^{\mathrm{T}}$ & 33 & 46 & NT & NT & 100 & 28 & NT & NT & 23 \\
\hline GIFU 7789 & 30 & 44 & 21 & NT & 73 & 31 & NT & NT & NT \\
\hline GIFU 7732 & 29 & NT & 28 & NT & 73 & NT & NT & NT & NT \\
\hline GIFU 7794 & 30 & 40 & NT & NT & 71 & 25 & NT & NT & 36 \\
\hline GIFU 7678 & 30 & 35 & 31 & NT & 37 & 39 & NT & 15 & NT \\
\hline
\end{tabular}




\begin{tabular}{|c|c|c|c|c|c|c|c|c|c|}
\hline GIFU 7695 & 31 & 42 & 25 & NT & 35 & 35 & NT & NT & NT \\
\hline GIFU 7954 & 33 & 21 & NT & NT & 35 & NT & NT & NT & NT \\
\hline \multicolumn{10}{|l|}{ Peptostreptococcus tetradius } \\
\hline GIFU $7672^{\mathrm{T}}$ & 30 & 37 & NT & NT & 24 & 100 & NT & NT & 27 \\
\hline GIFU 3282 & 32 & 43 & NT & NT & 24 & 96 & NT & NT & NT \\
\hline GIFU 3298 & 32 & 40 & NT & NT & 32 & 95 & NT & NT & NT \\
\hline GIFU 3270 & 32 & 37 & NT & NT & 22 & 76 & NT & NT & NT \\
\hline GIFU 7617 & 32 & 40 & NT & NT & 27 & 73 & NT & 27 & 31 \\
\hline \multicolumn{10}{|l|}{ Unclassified group P-1 } \\
\hline GIFU 7668 & 24 & 13 & NT & NT & 3 & NT & NT & NT & 12 \\
\hline GIFU 7878 & 24 & 2 & NT & NT & 0 & NT & NT & NT & NT \\
\hline \multicolumn{10}{|l|}{ Peptostreptococcus magnus } \\
\hline ATCC $15794^{\mathrm{T}}$ & 32 & NT & NT & NT & NT & NT & 100 & 95 & 36 \\
\hline GIFU 7726 & 32 & NT & NT & NT & NT & NT & 100 & 94 & NT \\
\hline GIFU 7795 & 32 & NT & NT & NT & NT & NT & 100 & 97 & NT \\
\hline GIFU 7943 & 33 & NT & NT & NT & NT & NT & 99 & 91 & NT \\
\hline GIFU 7711 & 33 & NT & NT & NT & NT & NT & 99 & 83 & 27 \\
\hline GIFU 7724 & 32 & NT & NT & NT & NT & NT & 98 & 97 & NT \\
\hline GIFU 7624 & 33 & NT & NT & NT & NT & NT & 98 & 85 & NT \\
\hline GIFU 7785 & 33 & NT & NT & NT & NT & NT & 98 & 83 & NT \\
\hline GIFU 7655 & 33 & NT & NT & NT & NT & NT & 98 & 82 & NT \\
\hline GIFU 7651 & 33 & NT & NT & NT & NT & NT & 98 & 82 & NT \\
\hline GIFU 7735 & 32 & NT & NT & NT & NT & NT & 98 & 78 & NT \\
\hline GIFU 7792 & 32 & NT & NT & NT & NT & NT & 97 & 77 & NT \\
\hline GIFU 7661 & 34 & NT & NT & NT & NT & NT & 85 & 76 & NT \\
\hline GIFU 7723 & 32 & NT & NT & NT & NT & NT & 79 & 85 & NT \\
\hline GIFU 7677 & 33 & NT & NT & NT & NT & NT & 79 & 72 & NT \\
\hline GIFU 7957 & 33 & NT & NT & NT & NT & NT & 70 & 68 & NT \\
\hline ATCC 14955 & 32 & NT & NT & NT & NT & 26 & 100 & 100 & 36 \\
\hline GIFU 7700 & 33 & NT & NT & NT & NT & NT & 93 & 99 & NT \\
\hline GIFU 7716 & 33 & NT & NT & NT & NT & NT & 90 & 98 & NT \\
\hline GIFU 7654 & 33 & NT & NT & NT & NT & NT & 97 & 83 & NT \\
\hline GIFU 7690 & 33 & NT & NT & NT & NT & NT & 77 & 74 & NT \\
\hline GIFU 7644 & 33 & NT & NT & NT & NT & NT & 71 & 73 & NT \\
\hline GIFU 7679 & 34 & NT & NT & NT & NT & NT & 67 & 74 & NT \\
\hline $\begin{array}{l}\text { Peptostreptococcus micros } \\
\text { VPI } 5464^{T}\end{array}$ & 28 & NT & NT & NT & NT & NT & NT & 18 & 21 \\
\hline $\begin{array}{l}\text { Staphylococcus saccharolyticus } \\
\text { ATCC } 14953^{\mathrm{T}}\end{array}$ & 31 & 4 & NT & NT & 4 & NT & 13 & NT & NT \\
\hline $\begin{array}{l}\text { Peptostreptococcus productus } \\
\text { ATCC } 27340^{\mathrm{T}}\end{array}$ & 45 & NT & NT & NT & NT & NT & NT & NT & 1 \\
\hline Streptococcus parvulus VPI $0546^{\mathrm{T}}$ & 44 & NT & NT & NT & NT & NT & NT & NT & 0 \\
\hline Peptococcus niger ATCC $27731^{\mathrm{T}}$ & 51 & 6 & NT & NT & 2 & 1 & 0 & NT & NT \\
\hline
\end{tabular}


TABLE 3. Biochemical characters of the 65 selected strains of anaerobic cocci

\begin{tabular}{|c|c|c|c|c|c|c|c|c|c|c|c|}
\hline Organism & $\begin{array}{l}\text { Metabolic end } \\
\text { product(s) } \\
\text { from } \mathrm{PYG}^{a}\end{array}$ & $\begin{array}{l}\text { In- } \\
\text { dole }\end{array}$ & $\begin{array}{l}\text { Co- } \\
\text { agu- } \\
\text { lase }\end{array}$ & $\begin{array}{l}\text { Nitrate } \\
\text { reduc- } \\
\text { tion }\end{array}$ & $\begin{array}{l}\text { Propio- } \\
\text { nate } \\
\text { from } \\
\text { lactate }\end{array}$ & $\begin{array}{l}\text { Gas } \\
\text { from } \\
\text { PYG }\end{array}$ & $\begin{array}{l}\text { Gelatin } \\
\text { lique- } \\
\text { faction }\end{array}$ & $\begin{array}{l}\text { Cata- } \\
\text { lase }\end{array}$ & Urease & $\begin{array}{l}\text { Starch } \\
\text { hydrol- } \\
\text { ysis }\end{array}$ & $\begin{array}{c}\text { Esculin } \\
\text { hydrol- } \\
\text { ysis }\end{array}$ \\
\hline $\begin{array}{l}\text { Peptostreptococcus } \\
\text { anaerobius } \\
\text { ATCC } 27337^{\mathrm{T}}\end{array}$ & IC, A, iv, ib & $-b$ & - & - & - & t & - & - & - & - & - \\
\hline \multicolumn{12}{|l|}{$\begin{array}{l}\text { Peptostreptococcus } \\
\text { asaccharolyticus } \\
\text { homology group } 1\end{array}$} \\
\hline ATCC $14963^{\mathrm{T}}$ & $B, a, p$ & + & - & - & - & t & - & + & - & - & - \\
\hline GIFU 3302 & $\mathrm{~B}, \mathrm{~A}$ & t & - & - & - & t & - & - & - & - & - \\
\hline GIFU 7877 & B, A & + & - & - & - & + & - & - & - & - & - \\
\hline GIFU 3306 & $\mathrm{~B}, \mathrm{~A}$ & + & - & - & - & + & - & - & - & - & - \\
\hline GIFU 6287 & $\mathrm{~B}, \mathrm{~A}, \mathrm{p}$ & + & - & - & - & + & - & + & - & - & - \\
\hline GIFU 3315 & $\mathrm{~B}, \mathrm{~A}$ & + & - & - & - & t & - & - & - & - & - \\
\hline GIFU 3290 & $\mathrm{~B}, \mathrm{~A}(\mathrm{p}, \mathrm{I})$ & + & - & - & - & + & - & - & - & - & - \\
\hline GIFU 7951 & $\mathrm{~B}, \mathrm{~A}$ & t & - & - & - & + & - & + & - & - & - \\
\hline \multicolumn{12}{|l|}{$\begin{array}{l}\text { Peptostreptococcus } \\
\text { asaccharolyticus } \\
\text { homology group } 2\end{array}$} \\
\hline GIFU 6663 & $\mathrm{~B}, \mathrm{~A}, \mathrm{p}$ & + & - & - & - & + & - & + & - & - & - \\
\hline GIFU 6291 & $\mathrm{~B}, \mathrm{~A}, \mathrm{p}$ & + & - & - & - & + & - & + & - & - & - \\
\hline GIFU 7871 & $B, A, p$ & + & - & - & - & + & - & - & - & - & - \\
\hline GIFU 7693 & B, A, 1 & + & - & - & - & + & - & - & - & - & - \\
\hline GIFU 7681 & $\mathrm{~B}, \mathrm{~A}$ & + & NT & - & NT & + & - & - & - & - & - \\
\hline GIFU 7939 & $\mathrm{~B}, \mathrm{~A}(\mathrm{p}, \mathrm{l})$ & + & - & - & - & + & - & - & - & - & - \\
\hline GIFU 7955 & $B, A, i v, i b$ & + & NT & - & NT & + & - & + & - & - & $w$ \\
\hline \multicolumn{12}{|l|}{ Unclassified group } \\
\hline A-1 & & & & & & & & & & & \\
\hline GIFU 1244 & $\mathrm{~B}, \mathrm{l}, \mathrm{a}, \mathrm{p}$ & + & - & - & - & t & - & - & - & - & - \\
\hline GIFU 7662 & $\mathrm{~B}, \mathrm{~L}, \mathrm{a}$ & + & - & - & - & + & - & + & - & - & - \\
\hline GIFU 7872 & $\mathrm{~B}, \mathrm{~L}, \mathrm{a}, \mathrm{p}$ & + & - & - & - & + & - & + & - & - & - \\
\hline \multicolumn{12}{|l|}{$\begin{array}{l}\text { Peptostreptococcus } \\
\text { indolicus }\end{array}$} \\
\hline ATCC $29427^{\mathrm{T}}$ & B, A, p & + & + & + & + & + & - & - & - & - & - \\
\hline GIFU 8287 & $\mathrm{~B}, \mathrm{~A}, \mathrm{p}$ & t & + & + & + & + & - & - & - & - & - \\
\hline GIFU 8288 & $\mathrm{~B}, \mathrm{~A}, \mathrm{p}$ & + & + & + & + & + & - & - & - & - & - \\
\hline GIFU 8296 & $\mathrm{~B}, \mathrm{~A}, \mathrm{p}$ & + & + & + & + & + & - & - & - & - & - \\
\hline \multicolumn{12}{|l|}{$\begin{array}{l}\text { Peptostreptococcus } \\
\text { prevotii }\end{array}$} \\
\hline ATCC $9321^{\mathrm{T}}$ & $\mathrm{B}, \mathrm{a}, \mathrm{p}$ & - & - & - & - & + & - & + & + & - & - \\
\hline GIFU 7789 & $\mathrm{~B}, \mathrm{~A}, \mathrm{p}$ & - & - & - & - & t & - & - & - & - & - \\
\hline GIFU 7732 & B, a (1) & - & NT & - & NT & + & - & - & - & - & - \\
\hline GIFU 7794 & $\mathrm{~B}, \mathrm{l}, \mathrm{a}, \mathrm{p}$ & - & NT & - & NT & + & - & + & - & - & $\mathrm{w}$ \\
\hline GIFU 7678 & $\mathrm{~B}, \mathrm{a}, \mathrm{I}$ & - & NT & - & NT & + & - & - & - & - & - \\
\hline GIFU 7695 & $B, a, p$ & - & NT & - & $\mathrm{NT}$ & + & - & + & - & - & - \\
\hline GIFU 7954 & $\mathrm{~B}, \mathrm{a}, \mathrm{p}$ & - & - & - & - & + & - & + & - & - & - \\
\hline \multicolumn{12}{|l|}{$\begin{array}{l}\text { Peptostreptococcus } \\
\text { tetradius }\end{array}$} \\
\hline GIFU $7672^{\mathrm{T}}$ & $B, L, a$ & - & - & - & - & + & - & - & + & - & - \\
\hline
\end{tabular}

of 44 to 45 mol\% $\left(T_{m}\right)(3,10,33)$. These $\mathrm{G}+\mathrm{C}$ values are somewhat higher than the values for other species of Peptostreptococcus. Recently, Peptostreptococcus parvulus has been transferred to the genus Streptococcus (3), but the taxonomic position of Peptostreptococcus productus has not yet been evaluated in detail.

Descriptions of four species of the genus Peptostreptococcus Kluyver and van Niel 1980. (i) Peptostreptococcus asaccharolyticus (Distaso 1912) comb. nov. emend. Cells are 0.5 to $1.6 \mu \mathrm{m}$ in diameter and occur in masses or pairs. Colonies range from 1 to $2 \mathrm{~mm}$ in diameter on sheep blood agar. In PYG broth, all strains produce butyric acid, and some strains occasionally produce acetic, propionic, or lactic acid; none produces propionate from lactate. Most strains produce ammonia from glutamate, threonine, and serine, but not from glycine. Most strains fail to produce acid from carbohydrates. Nitrate is not reduced, and coagulase is not produced.

Other characteristics of this species are given in Tables 3 and 4.

May be pathogenic.

Isolated from normal and pathological genital secretions, normal feces, purulent pleurisy, skin, and brain abscesses (34).

The $\mathrm{G}+\mathrm{C}$ content of the DNA is 30 to 34 $\operatorname{mol} \%\left(T_{m}\right)$. 
TABLE 3-Continued

\begin{tabular}{|c|c|c|c|c|c|c|c|c|c|c|c|c|c|}
\hline \multirow{2}{*}{$\begin{array}{l}\text { Am- } \\
\text { monia } \\
\text { from } \\
\text { gluta- } \\
\text { mate }\end{array}$} & \multirow{2}{*}{$\begin{array}{l}\text { Am- } \\
\text { monia } \\
\text { from } \\
\text { gly- } \\
\text { cine }\end{array}$} & \multicolumn{5}{|c|}{ Carbohydrate fermentation } & \multicolumn{7}{|c|}{ API ZYM tests } \\
\hline & & $\begin{array}{l}\text { Fruc- } \\
\text { tose }\end{array}$ & $\begin{array}{l}\text { Malt- } \\
\text { ose }\end{array}$ & $\begin{array}{l}\text { Man- } \\
\text { nose }\end{array}$ & $\begin{array}{l}\text { Su- } \\
\text { crose }\end{array}$ & $\begin{array}{l}\text { Glu- } \\
\text { cose }\end{array}$ & $\begin{array}{l}\text { Alkaline } \\
\text { phos- } \\
\text { phatase }\end{array}$ & $\begin{array}{c}\text { Esterase } \\
(\mathrm{C}-4)\end{array}$ & $\begin{array}{c}\text { Esterase } \\
\text { lipase } \\
(\mathrm{C}-8)\end{array}$ & $\begin{array}{l}\text { Leucine } \\
\text { aryl- } \\
\text { amidase }\end{array}$ & $\begin{array}{l}\beta-\text { Galac- } \\
\text { tosidase }\end{array}$ & $\begin{array}{c}\beta- \\
\text { Glucur- } \\
\text { onidase }\end{array}$ & $\begin{array}{c}\alpha- \\
\text { Gluco- } \\
\text { sidase }\end{array}$ \\
\hline- & - & - & w & $\mathrm{w}$ & w & $w$ & - & + & $w$ & - & - & - & + \\
\hline
\end{tabular}

\begin{tabular}{|c|c|c|c|c|c|c|c|c|c|c|c|c|}
\hline+ & - & - & - & - & - & - & - & - & - & - & - & - \\
\hline+ & - & - & - & - & - & - & - & - & - & - & - & - \\
\hline+ & - & - & - & - & - & - & - & - & - & - & - & - \\
\hline+ & - & - & - & - & - & - & - & - & - & - & - & - \\
\hline+ & - & - & - & - & - & - & - & - & - & - & - & - \\
\hline+ & - & - & - & - & - & - & - & - & - & - & - & - \\
\hline+ & - & - & - & - & - & - & - & - & - & - & - & - \\
\hline+ & - & - & - & - & - & - & - & - & - & - & - & - \\
\hline
\end{tabular}

\begin{tabular}{|c|c|c|c|c|c|c|c|c|c|c|c|c|c|}
\hline+ & - & - & - & - & - & - & $w$ & - & $w$ & - & - & - & - \\
\hline+ & - & - & - & - & - & - & $w$ & - & $w$ & - & - & - & - \\
\hline+ & - & - & - & - & - & - & - & - & - & - & - & - & - \\
\hline+ & - & - & - & - & - & + & w & - & w & - & - & - & - \\
\hline+ & - & - & - & - & - & - & - & - & - & - & - & - & - \\
\hline+ & - & - & - & - & - & - & $w$ & - & - & - & - & - & - \\
\hline+ & - & - & - & - & - & - & - & - & - & - & - & - & - \\
\hline- & - & - & - & - & - & + & + & w & $w$ & - & - & - & - \\
\hline- & - & - & - & - & - & + & + & - & - & - & - & - & - \\
\hline- & - & - & - & - & - & + & + & - & $w$ & - & - & - & - \\
\hline+ & - & - & - & - & - & - & + & - & - & - & - & - & - \\
\hline+ & - & - & - & - & - & - & + & - & - & - & - & - & - \\
\hline+ & - & - & - & - & - & - & + & - & - & - & - & - & - \\
\hline+ & - & - & - & - & - & - & + & - & - & - & - & - & - \\
\hline- & - & w & - & $\mathbf{w}$ & $w$ & $w$ & + & + & + & - & + & + & + \\
\hline- & - & w & $w$ & w & - & $w$ & + & - & - & $w$ & - & - & - \\
\hline- & - & - & w & - & - & + & + & - & - & w & - & - & - \\
\hline- & - & - & w & - & - & w & + & - & - & w & - & - & - \\
\hline- & - & - & w & w & - & + & + & - & - & w & - & - & - \\
\hline- & - & - & + & w & $w$ & + & + & - & - & w & - & - & - \\
\hline- & - & - & + & w & - & + & + & - & - & w & - & - & - \\
\hline- & - & + & + & + & + & + & - & - & w & w & - & + & w \\
\hline
\end{tabular}

The type strain is strain ATCC 14963.

Indole production by Peptostreptococcus asaccharolyticus and Peptostreptococcus indolicus is a key character which differentiates these species from other butyrate-producing peptostreptococci (Table 5).

In addition, the levels of DNA-DNA homology among 18 strains of Peptostreptococcus asaccharolyticus, which were identified according to the characteristics listed in the Anaerobe Laboratory Manual, 4th ed. (14), separated these strains into three homology groups (Table 2). Group 1 contained the type strain. The levels of DNA-DNA homology between the type strain
Peptostreptococcus asaccharolyticus and strains of group 2 were 32 to $58 \%$. Attempts to separate group 2 strains from group 1 strains biochemically were not successful. Some group 2 strains were misidentified as Peptostreptococcus prevotii because they were indole negative initially; however, these strains produced indole after successive transfers in GAM broth. They also produced ammonia from glutamate. Homology group 3 (unclassified group A-1 [Table 2]) consisted of three strains. These strains had slightly lower $\mathrm{G}+\mathrm{C}$ values than the members of the other groups of Peptostreptococcus asaccharolyticus, produced little or no ammonia 
TABLE 3. Biochemical characters of the 65 selected strains of anaerobic cocci-Continued

\begin{tabular}{|c|c|c|c|c|c|c|c|c|c|c|c|}
\hline Organism & $\begin{array}{l}\text { Metabolic end } \\
\text { product(s) } \\
\text { from } \mathrm{PYG}^{a}\end{array}$ & $\begin{array}{l}\text { In- } \\
\text { dole }\end{array}$ & $\begin{array}{l}\text { Co- } \\
\text { agu- } \\
\text { lase }\end{array}$ & $\begin{array}{l}\text { Nitrate } \\
\text { reduc- } \\
\text { tion }\end{array}$ & $\begin{array}{l}\text { Propio- } \\
\text { nate } \\
\text { from } \\
\text { lactate }\end{array}$ & $\begin{array}{l}\text { Gas } \\
\text { from } \\
\text { PYG }\end{array}$ & $\begin{array}{l}\text { Gelatin } \\
\text { lique- } \\
\text { faction }\end{array}$ & $\begin{array}{l}\text { Cata- } \\
\text { lase }\end{array}$ & Urease & $\begin{array}{l}\text { Starch } \\
\text { hydrol- } \\
\text { ysis }\end{array}$ & $\begin{array}{l}\text { Esculin } \\
\text { hydrol- } \\
\text { ysis }\end{array}$ \\
\hline GIFU 3282 & B, L, a & - & - & - & - & + & - & + & + & - & - \\
\hline GIFU 3298 & $\mathrm{~B}, \mathrm{~L}, \mathrm{a}$ & - & - & - & - & t & - & + & + & - & - \\
\hline GIFU 3270 & $\mathrm{~B}, \mathrm{~L}$ & - & - & - & - & + & - & - & + & - & w \\
\hline GIFU 7617 & $\mathrm{~B}, \mathrm{~L}$ & - & - & - & - & + & - & - & + & - & $w$ \\
\hline \multicolumn{12}{|l|}{ Unclassified group } \\
\hline GIFU 7668 & B, A, 1 & - & NT & - & NT & + & - & - & - & - & - \\
\hline GIFU 7878 & $B, A, i v$ & - & NT & - & NT & + & - & - & - & - & - \\
\hline \multicolumn{12}{|l|}{$\begin{array}{l}\text { Peptostreptococcus } \\
\text { magnus }\end{array}$} \\
\hline ATCC $15794^{\mathrm{T}}$ & A & - & - & - & - & - & + & + & - & - & - \\
\hline GIFU 7726 & A & - & - & - & NT & - & + & + & - & - & - \\
\hline GIFU 7795 & A & - & NT & - & NT & - & + & + & - & - & - \\
\hline GIFU 7943 & A & - & - & - & - & - & + & + & - & - & - \\
\hline GIFU 7711 & A & - & NT & - & NT & - & + & + & - & - & - \\
\hline GIFU 7724 & A & - & - & - & - & -- & + & - & - & - & - \\
\hline GIFU 7624 & A & - & NT & - & NT & - & + & - & - & - & - \\
\hline GIFU 7785 & A & - & - & - & NT & - & + & - & - & - & - \\
\hline GIFU 7655 & A & - & NT & - & NT & - & + & + & - & - & - \\
\hline GIFU 7651 & A & - & - & - & - & - & + & + & - & - & - \\
\hline GIFU 7735 & A & - & NT & - & NT & - & + & + & - & - & - \\
\hline GIFU 7792 & A & - & - & - & - & - & + & + & - & - & - \\
\hline GIFU 7661 & A & - & - & - & NT & - & + & + & - & - & - \\
\hline GIFU 7723 & A & - & - & - & - & - & + & - & - & - & - \\
\hline GIFU 7677 & A & - & NT & - & NT & - & t & + & - & - & - \\
\hline GIFU 7957 & A & - & NT & - & NT & - & + & + & - & - & - \\
\hline ATCC 14955 & A & - & - & - & - & - & - & + & - & - & - \\
\hline GIFU 7700 & A & -- & NT & - & NT & - & - & + & - & - & - \\
\hline GIFU 7716 & A & - & - & - & NT & - & - & + & - & - & - \\
\hline GIFU 7654 & A & - & NT & - & NT & - & - & + & - & - & - \\
\hline GIFU 7690 & A & - & NT & - & NT & - & - & + & - & - & - \\
\hline GIFU 7644 & A & - & NT & - & NT & - & - & - & - & - & - \\
\hline GIFU 7679 & A & - & NT & - & NT & - & - & + & - & - & - \\
\hline $\begin{array}{l}\text { Peptostreptococcus } \\
\text { micros VPI } 5464^{\mathrm{T}}\end{array}$ & A, s, 1 & - & - & - & - & - & - & - & - & - & - \\
\hline $\begin{array}{l}\text { Staphylococcus } \\
\text { saccharolyticus } \\
\text { ATCC } 14953^{\mathrm{T}}\end{array}$ & A & - & - & + & - & + & - & + & + & - & - \\
\hline $\begin{array}{l}\text { Peptostreptococcus } \\
\text { productus ATCC } \\
27340^{\mathrm{T}}\end{array}$ & A, s & - & - & - & - & + & - & - & - & - & + \\
\hline $\begin{array}{l}\text { Streptococcus par- } \\
\text { vulus VPI } 0546^{\mathrm{T}}\end{array}$ & $\mathrm{L}, \mathrm{a}$ & - & - & - & - & - & - & - & - & - & + \\
\hline $\begin{array}{l}\text { Peptococcus niger } \\
\text { ATCC } 27731^{\mathrm{T}}\end{array}$ & $\mathrm{B}, \mathrm{C}, \mathrm{iv}, \mathrm{a}$ & - & - & - & - & $w$ & - & - & - & - & - \\
\hline
\end{tabular}

" a and A, Acetic acid; C, caproic acid; B, butyric acid; 1 and L. lactic acid; ib, isobutyric acid; iv, isovaleric acid; IC, isocaproic acid; $p$, propionic acid; $s$, succinic acid. The capital letters indicate major products, and the lower-case letters indicate minor products. The products in parentheses are occasional products.

$b+$, Positive; -, negative; w, weakly positive; NT, not tested.

from glutamate, and produced acid from glucose (Table 3) and alkaline phosphatase in GAM broth. These biochemical characteristics clearly separate the group 3 strains from the strains of the other two homology groups.

In a study of indole-positive anaerobic cocci by Huss et al. (17), five strains of Peptococcus asaccharolyticus were used. These authors referred to Peptostreptococcus asaccharolyticus ATCC $14963^{\mathrm{T}}(\mathrm{T}=$ type strain) as "Peptococcus aerogenes" and to the four other strains as Peptococcus asaccharaolyticus. The $\mathrm{G}+\mathrm{C}$ con- tent of the DNA of the type strain was $31 \mathrm{~mol} \%$, and the $\mathrm{G}+\mathrm{C}$ contents of the four other strains ranged from 36 to $38 \mathrm{~mol} \%$. The levels of DNADNA homology between the type strain and the four other strains were less than $25 \%$.

(ii) Peptostreptococcus indolicus (Christiansen 1934) comb. nov. Cells are 0.7 to $1.6 \mu \mathrm{m}$ in diameter and occur in masses or in pairs. Colonies on sheep blood agar are 1 to $2 \mathrm{~mm}$ in diameter, circular, and smooth. All strains produce propionate from lactate, coagulase, and indole, reduce nitrate to nitrite, and produce 
TABLE 3-Continued

\begin{tabular}{|c|c|c|c|c|c|c|c|c|c|c|c|c|c|}
\hline \multirow{2}{*}{$\begin{array}{l}\text { Am- } \\
\text { monia } \\
\text { from } \\
\text { gluta- } \\
\text { mate }\end{array}$} & \multirow{2}{*}{$\begin{array}{l}\text { Am- } \\
\text { monia } \\
\text { from } \\
\text { gly- } \\
\text { cine }\end{array}$} & \multicolumn{5}{|c|}{ Carbohydrate fermentation } & \multicolumn{7}{|c|}{ API ZYM tests } \\
\hline & & $\begin{array}{l}\text { Fruc- } \\
\text { tose }\end{array}$ & $\begin{array}{l}\text { Malt- } \\
\text { ose }\end{array}$ & $\begin{array}{l}\text { Man- } \\
\text { nose }\end{array}$ & $\begin{array}{l}\text { Su- } \\
\text { crose }\end{array}$ & $\begin{array}{l}\text { Glu- } \\
\text { cose }\end{array}$ & $\begin{array}{c}\text { Alkaline } \\
\text { phos- } \\
\text { phatase }\end{array}$ & $\begin{array}{c}\text { Esterase } \\
(\mathrm{C}-4)\end{array}$ & $\begin{array}{c}\text { Esterase } \\
\text { lipase } \\
(\mathrm{C}-8)\end{array}$ & $\begin{array}{c}\text { Leucine } \\
\text { aryl- } \\
\text { amidase }\end{array}$ & $\begin{array}{l}\beta \text {-Galac- } \\
\text { tosidase }\end{array}$ & $\begin{array}{c}\beta- \\
\text { Glucur- } \\
\text { onidase }\end{array}$ & $\begin{array}{c}\alpha- \\
\text { Gluco- } \\
\text { sidase }\end{array}$ \\
\hline- & - & + & + & + & + & + & - & - & - & - & - & + & w \\
\hline- & - & + & + & + & + & + & - & - & - & - & - & + & $w$ \\
\hline- & - & + & + & + & + & + & - & - & - & - & - & + & w \\
\hline- & - & + & + & + & + & + & - & - & - & - & - & + & $w$ \\
\hline+ & - & - & - & - & - & - & - & - & - & - & - & - & - \\
\hline+ & - & - & - & - & - & - & - & - & - & - & - & - & - \\
\hline- & + & w & - & - & - & - & + & + & $w$ & + & - & - & - \\
\hline- & + & w & - & - & - & $w$ & + & + & $w$ & + & - & - & - \\
\hline- & + & - & - & - & - & - & $w$ & + & $w$ & + & - & - & - \\
\hline- & + & + & - & - & - & - & + & + & $\mathrm{w}$ & + & - & - & - \\
\hline- & + & - & - & - & - & - & $w$ & + & $w$ & + & - & - & - \\
\hline- & + & + & - & - & - & $w$ & + & + & $w$ & + & - & - & - \\
\hline- & + & - & - & - & - & - & $w$ & $w$ & - & $w$ & - & - & - \\
\hline- & + & $w$ & - & - & - & - & + & + & w & + & - & - & - \\
\hline- & + & - & - & - & - & w & w & + & $w$ & + & - & - & - \\
\hline- & + & + & - & - & - & - & $w$ & $w$ & $w$ & + & - & - & - \\
\hline- & + & + & - & - & - & - & $w$ & + & $w$ & + & - & - & - \\
\hline- & + & + & - & - & - & - & w & w & $w$ & + & - & - & - \\
\hline- & + & + & - & - & - & - & w & + & + & + & - & - & - \\
\hline- & + & + & - & - & - & - & + & $\mathrm{w}$ & w & + & - & - & - \\
\hline- & + & - & - & - & - & - & w & + & $w$ & + & - & - & - \\
\hline- & + & - & - & - & - & - & w & + & w & + & - & - & - \\
\hline- & + & w & - & - & - & - & $w$ & + & + & $w$ & - & - & - \\
\hline- & + & w & - & - & - & - & w & + & + & + & - & - & - \\
\hline- & + & w & - & - & - & - & w & $w$ & - & + & - & - & - \\
\hline- & + & w & - & - & - & - & w & + & + & $\mathrm{w}$ & - & - & - \\
\hline- & + & $w$ & - & - & - & - & w & + & + & w & - & - & - \\
\hline- & + & w & - & - & - & - & w & + & + & w & - & - & - \\
\hline- & + & $w$ & - & - & - & - & $\mathrm{w}$ & + & + & + & - & - & - \\
\hline- & $w$ & - & - & - & - & - & + & w & + & + & - & - & - \\
\hline- & - & + & - & + & - & + & - & + & + & - & - & - & - \\
\hline- & - & + & + & + & + & + & - & + & + & - & + & - & + \\
\hline- & - & + & + & + & - & + & - & - & - & - & - & - & - \\
\hline- & - & - & - & - & - & - & NT & NT & NT & NT & NT & NT & NT \\
\hline
\end{tabular}

butyric acid in PYG broth. Occasionally, some strains also produce acetic and propionic acids in PYG broth. All strains produce ammonia from glutamate, threonine, and serine, but not from glycine. All strains fail to produce acid from carbohydrates.

Other characteristics of the species are given in Tables 3 and 4 and by Høi-Sorenson (13) and other authors $(6,17)$.

May be pathogenic for animals.

Isolated from cattle, swine, and rats. Isolation of Peptostreptococcus indolicus from a human clinical specimen has been reported (1).

The $\mathrm{G}+\mathrm{C}$ content of the DNA is 32 to 33 $\operatorname{mol} \%\left(T_{m}\right)$.
The type strain is strain ATCC 29427.

Coagulase production, nitrate reduction, and propionate production from lactate are key characters for separating this species from Peptostreptococcus asaccharolyticus (Table 5). An occasional strain does not produce coagulase (37) or reduce nitrate (14).

(iii) Peptostreptococcus prevotii (Foubert and Douglas 1948) comb. nov. emend. Cells are 0.7 to $1.8 \mu \mathrm{m}$ in diameter and occur in pairs, tetrads, or short chains. Hemolytic strains occasionally are observed on horse blood agar. Colonies range from 0.5 to $2 \mathrm{~mm}$ in diameter on sheep blood agar. All strains fail to produce coagulase or indole and to reduce nitrate. Many strains 
TABLE 4. Major cellular fatty acids and aldehyde of 23 strains of anaerobic cocci

\begin{tabular}{|c|c|c|c|c|c|}
\hline \multirow{2}{*}{ Organism } & \multicolumn{5}{|c|}{ Major fatty acids and aldehyde $(\% \text { of total acids })^{a}$} \\
\hline & $\mathrm{C} 15: \mathrm{Br}$ & C16:0 & $\mathrm{C} 17: 1$ & C18:1 & C18:1 aldehyde \\
\hline Peptostreptococcus anaerobius ATCC $27337^{\mathrm{T}}$ & 0 & 16 & $\mathrm{~T}^{h}$ & 65 & 12 \\
\hline \multicolumn{6}{|l|}{$\begin{array}{l}\text { Peptostreptococcus asaccharolyticus } \\
\text { Pello }\end{array}$} \\
\hline ATCC $14963^{\mathrm{T}}$ & 0 & $\mathrm{~T}$ & 0 & 74 & 21 \\
\hline GIFU 7955 & 0 & $\mathrm{~T}$ & $\mathrm{~T}$ & 75 & 20 \\
\hline GIFU 6663 & 0 & $\mathrm{~T}$ & $\mathrm{~T}$ & 70 & 25 \\
\hline Unclassified group A-1 strain GIFU 1244 & 0 & $\mathrm{~T}$ & 0 & 74 & 21 \\
\hline \multicolumn{6}{|l|}{ Peptostreptococcus indolicus } \\
\hline ATCC $29428^{\mathrm{T}}$ & 0 & 1 & 0 & 87 & 7 \\
\hline GIFU 8288 & 0 & 2 & 0 & 88 & 5 \\
\hline GIFU 8296 & 0 & 2 & $\mathrm{~T}$ & 85 & 5 \\
\hline \multicolumn{6}{|l|}{ Peptostreptococcus prevotii } \\
\hline ATCC $9321^{\mathrm{T}}$ & 0 & $\mathrm{~T}$ & 0 & 61 & 35 \\
\hline GIFU 7794 & 0 & $\mathrm{~T}$ & $T$ & 60 & 39 \\
\hline GIFU 7954 & 0 & $\mathrm{~T}$ & $\mathrm{~T}$ & 73 & 26 \\
\hline Unclassified group P-1 strain GIFU 7668 & 0 & 3 & $\mathrm{~T}$ & 72 & 25 \\
\hline \multicolumn{6}{|l|}{ Peptostreptococcus tetradius } \\
\hline GIFU $7672^{\mathrm{T}}$ & 0 & $\mathrm{~T}$ & $\mathrm{~T}$ & 85 & $\mathrm{~T}$ \\
\hline GIFU 3284 & 0 & 1 & 0 & 82 & 6 \\
\hline GIFU 7617 & 0 & $\mathrm{~T}$ & 0 & 88 & 7 \\
\hline \multicolumn{6}{|l|}{ Peptostreptococcus magnus } \\
\hline ATCC $15794^{\mathrm{T}}$ & 0 & 20 & 0 & 62 & 12 \\
\hline GIFU 7624 & 0 & $\mathrm{~T}$ & 0 & 74 & 21 \\
\hline ATCC 14955 & 0 & 15 & 0 & 73 & 2 \\
\hline GIFU 7644 & 0 & $\mathrm{~T}$ & $\mathrm{~T}$ & 69 & 26 \\
\hline Peptostreptococcus micros VPI $5464^{\mathrm{T}}$ & 0 & $\mathrm{~T}$ & 0 & 70 & 28 \\
\hline Peptostreptococcus productus ATCC $27340^{\mathrm{T}}$ & 0 & 7 & 28 & 29 & 3 \\
\hline Streptococcus parvulus VPI $0546^{\mathrm{T}}$ & 0 & 7 & 28 & 61 & 3 \\
\hline Staphylococcus saccharolyticus ATCC $14953^{\mathrm{T}}$ & 0 & 2 & 0 & 30 & $\mathrm{~T}$ \\
\hline
\end{tabular}

${ }^{a}$ The number to the left of the colon indicates the number of carbon atoms. Br to the right of the colon indicates a branched-chain acid, 0 indicates a saturated acid, and 1 indicates an unsaturated acid.

${ }^{b} \mathrm{~T}$, Trace $(<1 \%)$.

produce trace amounts of catalase. Major metabolic end products from PYG broth cultures are butyrate, lactate, and acetate; an occasional strain also may produce propionate. Most strains produce ammonia from threonine and serine, but not from glycine. Some strains produce ammonia from glutamate. Some strains weakly ferment glucose, fructose, mannose, maltose, or sucrose. Most strains do not ferment arabinose, cellobiose, lactose, mannitol, raffinose, rhamnose, trehalose, or xylose.

Other characteristics of this species are given in Tables 3 and 4.

Members of the normal floras of skin, oral cavities, guts, and vaginas. Isolated from pathological vaginal secretions and lung abscesses.

The $\mathrm{G}+\mathrm{C}$ content of the DNA ranges from 29 to $33 \mathrm{~mol} \%\left(T_{m}\right)$.

The type strain is strain ATCC 9321.

Peptostreptococcus prevotii is easily separated from other butyrate-producing Peptostreptococcus species by the characters shown in Tables 3 and 5. However, Peptostreptococcus asaccharolyticus strains sometimes may be misidentified as Peptostreptococcus prevotii be- cause their indole production is often feeble and indole is not detected unless it is extracted with xylene before the reagent is added. Production of indole and ammonia from glutatmate by Peptostreptococcus asaccharaolyticus is helpful for differentiating this species from Peptostreptococcus prevotii.

In addition, DNA-DNA homologies between the type strain and clinical isolates of Peptostreptococcus prevotii and determinations of the DNA base contents of these strains revealed heterogeneity among the strains of this species (Table 2). The levels of homology between the type strain and three clinical isolates (GIFU 7678, GIFU 7695, and GIFU 7954) were 35 to $37 \%$. Phenotypic differentiation of these strains from the type strain was not successful (Table 3 ). We think that these strains should be retained in Peptostreptococcus prevotii until useful biochemical characteristics are available to separate them from the type species.

Two genetically unrelated strains, strains GIFU 7668 and GIFU 7878, were tentatively identified as Peptostreptococcus prevotii according to the Anaerobe Laboratory Manual, 
TABLE 5. Key characters to separate the species of the genus Peptostreptococcus

\begin{tabular}{|c|c|c|c|c|c|c|c|c|c|c|c|c|c|c|c|c|c|}
\hline \multirow{2}{*}{ Organism } & \multirow{2}{*}{$\begin{array}{c}\mathrm{G}+\mathrm{C} \\
\text { content } \\
(\mathrm{mol} \%)^{a}\end{array}$} & \multirow{2}{*}{$\begin{array}{l}\text { Metabolic } \\
\text { end } \\
\text { product(s) } \\
\text { from } \mathrm{PYG}^{b}\end{array}$} & \multirow{2}{*}{$\begin{array}{l}\text { Indole } \\
\text { produc- } \\
\text { tion }\end{array}$} & \multirow{2}{*}{$\begin{array}{l}\text { Nitrate } \\
\text { reduc- } \\
\text { tion }\end{array}$} & \multirow{2}{*}{$\begin{array}{l}\text { Coagulase } \\
\text { produc- } \\
\text { tion }\end{array}$} & \multirow{2}{*}{$\begin{array}{c}\text { Urease } \\
\text { produc- } \\
\text { tion }\end{array}$} & \multirow{2}{*}{$\begin{array}{l}\text { Milk } \\
\text { coagu- } \\
\text { lation }\end{array}$} & \multirow{2}{*}{$\begin{array}{c}\text { Gelatin } \\
\text { diges- } \\
\text { tion }\end{array}$} & \multicolumn{6}{|c|}{ Carbohydrate fermentation } & \multirow{2}{*}{$\begin{array}{c}\text { Am- } \\
\text { monia } \\
\text { from } \\
\text { glycine }\end{array}$} & \multirow{2}{*}{$\begin{array}{l}\text { Ammonia } \\
\text { from } \\
\text { glutamate }\end{array}$} & \multirow{2}{*}{$\begin{array}{l}\text { Gas } \\
\text { from } \\
\text { PYG }\end{array}$} \\
\hline & & & & & & & & & $\begin{array}{l}\text { Cello- } \\
\text { biose }\end{array}$ & $\begin{array}{l}\text { Glu- } \\
\text { cose }\end{array}$ & $\begin{array}{l}\text { Lac- } \\
\text { tose }\end{array}$ & $\begin{array}{l}\text { Malt- } \\
\text { ose }\end{array}$ & $\begin{array}{c}\text { Su- } \\
\text { crose }\end{array}$ & $\begin{array}{l}\text { Man- } \\
\text { nose }\end{array}$ & & & \\
\hline $\begin{array}{l}\text { Peptostreptococcus } \\
\text { anaerobius }\end{array}$ & $33-34$ & $\begin{array}{l}\text { IC, A (iv, } \\
\text { ib, b) }\end{array}$ & $-c$ & - & - & - & - & - & - & (w) & - & (w) & (w) & - & - & $(-)$ & + \\
\hline $\begin{array}{l}\text { Peptostreptococcus } \\
\text { magnus }\end{array}$ & $32-34$ & A & - & - & - & - & - & $\mathrm{v}$ & - & $(-)$ & - & - & - & - & + & $(-)$ & - \\
\hline $\begin{array}{l}\text { Peptostreptococcus } \\
\text { micros }\end{array}$ & $28-29$ & $A(s)$ & - & - & - & - & - & - & - & - & - & - & - & - & $(-)$ & - & - \\
\hline $\begin{array}{l}\text { Peptostreptococcus } \\
\text { indolicus }\end{array}$ & $33-34$ & $\mathrm{~B}(\mathrm{~A}, \mathrm{l}, \mathrm{p})$ & + & $(+)$ & $(+)$ & - & - & - & - & - & - & - & - & - & - & + & + \\
\hline $\begin{array}{c}\text { Peptostreptococcus } \\
\text { asaccharolyticus }\end{array}$ & $30-34$ & $\mathrm{~B}(\mathrm{~A}, 1, \mathrm{p})$ & + & - & - & - & - & - & - & $(-)$ & - & - & - & - & - & + & + \\
\hline $\begin{array}{l}\text { Peptostreptococcus } \\
\text { prevotii }\end{array}$ & $29-33$ & $\begin{array}{l}\text { B (L, A, } \\
\text { p) }\end{array}$ & - & - & - & $(-)$ & - & - & - & (w) & - & (w) & (w) & (w) & - & $(-)$ & + \\
\hline $\begin{array}{l}\text { Peptostreptococcus } \\
\text { tetradius }\end{array}$ & $30-32$ & $\mathrm{~L}, \mathrm{~B}(\mathrm{a}, \mathrm{p})$ & - & - & - & + & - & - & - & + & - & + & + & + & - & $(-)$ & + \\
\hline $\begin{array}{l}\text { Peptostreptococcus } \\
\text { productus }\end{array}$ & 45 & A, $1, s$ & - & - & - & - & + & - & + & + & + & + & + & + & - & + & + \\
\hline
\end{tabular}

${ }^{a}$ As determined by the $T_{m}$ method.

${ }^{b} \mathrm{a}$ and $\mathrm{A}$, Acetic acid; $\mathrm{b}$ and $\mathrm{B}$, butyric acid; IC, isocaproic acid; iv, isovaleric acid; ib, isobutyric acid; s, succinic acid; 1 and $\mathrm{L}$, lactic acid; $\mathrm{p}$, propionic acid. The capital letters indicate major products, and the lower-case letters indicate minor products. The products in parentheses are occasional products.

$c+$, Positive; - , negative; $(+)$, negative strains may exist; $(-)$, most strains are negative $(>90 \%) ; \mathrm{v}, 68 \%$ of the strains tested are positive; $(\mathrm{w}), 15$ to $90 \%$ of the strains are weakly positive.

${ }^{d}$ Cell size, soluble proteins, and alkaline phosphatase are used to differentiate Peptostreptococcus magnus and Peptostreptococcus micros (see text).

e Propionate production from lactate is helpful in differentiating Peptostreptococcus indolicus from Peptostreptococcus asaccharolyticus (14). 
4th ed., but were finally excluded from Peptostreptococcus prevotii because of their low $\mathrm{G}+\mathrm{C}$ values $(22 \mathrm{~mol} \%)$. These strains are listed as unclassified group P-1 in Tables 1 through 4. One strain was isolated from the lacrimal sac of a newborn baby, and the other was isolated from a uterine cavity. Both strains grew slowly in PYG medium and died within 5 to 7 days when they were kept in PYG medium or chopped meat medium at room temperature. Production of ammonia from glutamate and the lack of an alkaline phosphatase separate the two strains of group P-1 from Peptostreptococcus prevotii.

(iv) Peptostreptococcus magnus (Prévot 1933) Smith 1957 comb. rev. Cells are 0.8 to $1.6 \mu \mathrm{m}$ in diameter and occur predominantly in masses but occasionally in pairs or short chains. Colonies on sheep blood agar range from pinpoint to 1.2 $\mathrm{mm}$ in diameter. No strain produces coagulase or indole. No strain reduces nitrate. Many strains show feeble catalase activity. All strains produce acetic acid but not butyric or caproic acid from PYG broth. All strains produce ammonia from glycine. Most strains produce ammonia from threonine and serine.

Other characteristics are given in Tables 3 and 4.

May be pathogenic for humans.

Often isolated from human infections, including lung, brain, ovarian, and skin abscesses, endometritis, sepsis, and peritonitis, and from normal feces and vaginas.

The $\mathrm{G}+\mathrm{C}$ content of the DNA is 32 to 34 $\operatorname{mol} \%\left(T_{m}\right)$.

The type strain is strain ATCC 15794.

Peptostreptococcus magnus can be differentiated from anaerobic strains of Staphylococcus saccharolyticus by nitrate reduction, urease, and mannose fermentation tests (Table 5). Differentiation of Peptostreptococcus magnus from Peptostreptococcus micros is sometimes difficult. Peptostreptococcus micros is smaller than $0.6 \mu \mathrm{m}(14)$; the small cell size of this species has been used to differentiate it from Peptostreptococcus magnus (14). It has been reported that the inability of Peptostreptococcus magnus to produce alkaline phosphatase is helpful in differentiating these two species $(4,30)$. In our study, Peptostreptococcus magnus strains had generally weak alkaline phosphatase activities (Table 3), whereas strains of Peptostreptococcus micros had strong activities. Gel electrophoretic patterns of soluble proteins also may be helpful in differentiating these two species (4). Occasionally, gelatin liquefaction and catalase activity of Peptostreptococcus magnus are helpful in separating the two species.

In addition, DNA-DNA homology studies among the type strain Peptostreptococcus magnus and clinical isolates revealed that there is little genetic heterogeneity among the strains generally recognized as Peptostreptococcus magnus. There was no difference between gelatin-negative strains and gelatin-positive strains $(8,19)$.

History of "Gaffkya anaerobia" and proposal of Peptostreptococcus tetradius sp. nov. "Gaffkya anaerobia" was first described by Choukevitch as "Tetracoccus anaerobius" (5). This species also appeared in the 6th edition of Bergey's Manual under the name "Gaffkya anaerobia" (Choukevitch) Prévot (16). However, the name "Gaffkya anaerobia" (Choukevitch) Prévot lost standing in nomenclature when the generic name "Gaffkya" was placed on the list of rejected names by the Judicial Commission (18). "G. anaerobia" 'was a genetically and biochemically distinct species both in a previous study (9) and in this study. Our isolates did not survive heat treatment at $70^{\circ} \mathrm{C}$ for $15 \mathrm{~min}$. The cells were generally less than $1.8 \mu \mathrm{m}$ in diameter and did not occur in clusters of eight or more. Carbohydrates did not stimulate the growth of these organisms, so they are not members of the genus Sarcina. They produced butyric acid from PYG medium but did not require fermentable carbohydrates, so they are not members of the genus Coprococcus (15). Genetic and biochemical evidence indicates that the species should be placed in the genus Peptostreptococcus. Peptostreptococcus tetradius sp. nov. (te.tra'di.us. Gr. adj. tetradios by fours; N. L. masc. adj. tetradius occurring in groups of four) is proposed for this group of strains.

Description of Peptostreptococcus tetradius sp. nov. Cells are 0.8 to $1.8 \mu \mathrm{m}$ in diameter and occur mostly in pairs or tetrads, occasionally in short chains or masses (Fig. 1). Colonies on sheep blood agar range from pinpoint to $1.2 \mathrm{~mm}$ in diameter. Obligately anaerobic. Strains are nonhemolytic and make no black colonies on either rabbit or sheep blood agar after 7 days of anaerobic incubation. The major metabolic end products in PYG broth cultures are butyrate and lactate. No strain produces coagulase or indole or reduces nitrate. Catalase production is variable among strains. All strains produce urease and ferment fructose, glucose, maltose, mannose, and sucrose. They do not make acid from arabinose, cellobiose, esculin, lactose, mannitol, raffinose, rhamnose, or sorbitol. They produce ammonia from threonine and serine, but not from glycine.

Other characteristics of this species are given in Tables 3 and 4.

The pathogenicity is unknown.

Isolated from human vaginal discharge and various purulent secretions.

The $\mathrm{G}+\mathrm{C}$ content of the DNA is 30 to 32 $\operatorname{mol} \%\left(T_{m}\right)$. 


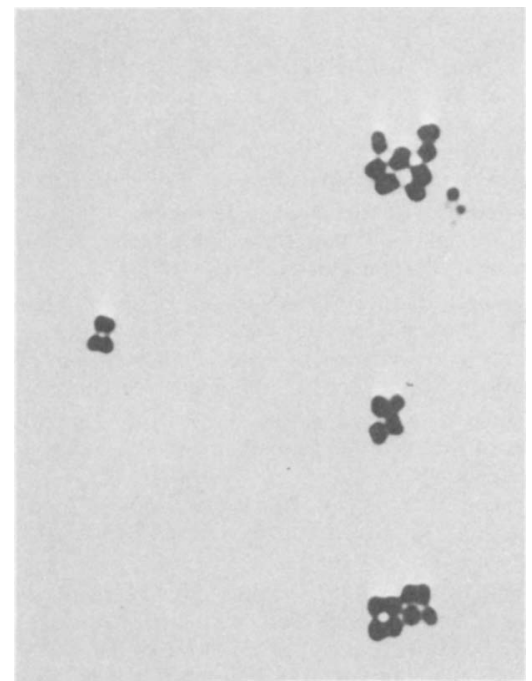

FIG. 1. Peptostreptococcus tetradius. $\times 2,000$.

The type strain is strain GIFU 7672 (= ATCC $35098=$ JCM 1964 = CCM 3634).

Tetrad formation is not always observed and cannot be used as a distinctive trait to separate this species from other anaerobic cocci. Urease and $\beta$-glucuronidase activities and fermentation of fructose, glucose, maltose, mannose, and sucrose are useful characters for separating $P e p$ tostreptococcus tetradius from Peptostreptococcus prevotii.

\section{ACKNOWLEDGMENTS}

We are grateful to J. L. Johnson for excellent support for the DNA-DNA hybridization experiments and to L. V. Holdeman and W. E. C. Moore (Anaerobe Laboratory, Virginia Polytechnic Institute and State University) for valuable advice. We thank I. Yano (Department of Microbiology, Niigata University, Niigata, Japan) for gas-liquid chromatographymass spectrometric analyses. We also thank K. Zimmerman (Swedish University of Agricultural Science, Uppsala, Sweden) and T. Oguri (Juntendo University Hospital, Tokyo, Japan) for valuable cultures.

Part of this work was supported by a grant-in-aid for scientific research (project 448155 ) from the Ministry of Education, Science and Culture, Japan.

\section{LITERATURE CITED}

1. Bourgault. A. M., and J. E. Rosenblatt. 1979. First isolation of Peptococcus indolicus from a human clinical specimen. J. Clin. Microbiol. 9:549-550.

2. Cardon, B. P., and H. A. Barker. 1946. Two new amino acid-fermenting bacteria, Clostridium propionicum and Diplococcus glycinophilus. J. Bacteriol. 52:629-634.

3. Cato, E. P. 1983. Transfer of Peptostreptococcus parvulus (Weinberg, Nativelle, and Prévot 1937) Smith 1957 to the genus Streptococcus: Streptococcus parvulus (Weinberg, Nativelle, and Prévot 1937) comb. nov., nom. rev., emend. Int. J. Syst. Bacteriol. 33:82-84.

4. Cato, E. P., J. L. Johnson, D. E. Hash, and L. V. Holdeman. 1983. Synonomy of Peptococcus glycinophilus (Cardon and Barker 1946) Douglas 1957 with Peptostreptococ- cus micros (Prévot 1933) Smith 1957 and electrophoretic differentiation of Peptostreptococcus micros from Peptococcus magnus. Int. J. Syst. Bacteriol. 33:207-210.

5. Choukévitch, J. 1911. Étude de la flore bactérienne du gros intestin du cheval. Ann. Inst. Pasteur Paris 25:345368.

6. Christiansen, M. 1934. Ein obligat anaërober, gasbildender, indolpositiver Mikrokokkus (Micrococcus indolicus n. sp.). Acta Pathol. Microbiol. Scand. Suppl. 18:4263.

7. Crosa, J. H., B. L. Williams, J. J. Jorgensen, and C. A Evans. 1979. Comparative study of deoxyribonucleic acid homology and physiological characteristics of strains of Peptococcus saccharolyticus. Int. J. Syst. Bacteriol. 29:328-332.

8. Douglas, H. C. 1957. Genus VI. Peptococcus Kluyver and van Niel, 1936, p. 474-480. In R. S. Breed, E. G. D. Murray, and N. R. Smith (ed.), Bergey's manual of determinative bacteriology, 7th ed. The Williams \& Wilkins Co., Baltimore.

9. Ezaki, T. 1982. Mol\% guanine plus cytosine of butyrate producing anaerobic cocci and DNA-DNA relationships among them. Jpn. J. Bacteriol. 37:607-613. (In Japanese.)

10. Ezaki, T., and E. Yabuuchi. 1983. Deoxyribonucleic acid base composition and DNA/DNA hybridization studies among the four species of Peptostreptococcus Kluyver and Van Niel 1936. FEMS Microbiol. Lett. 17:197-200.

11. Ezaki, T., and S. Suzuki. 1982. Archromopeptidase for lysis of anaerobic gram-positive cocci. J. Clin. Microbiol. 16:844-846.

12. Gillespie, L., and S. Spiegelman. 1965. A quantitative assay for DNA/RNA hybrids with DNA immobilized on a membrane. J. Mol. Biol. 12:829-842.

13. Høi-Sørenson, G. 1973. Micrococcus indolicus. Some biochemical properties, and the demonstration of six antigen ically different types. Acta Vet. Scand. 14:301-326.

14. Holdeman, L. V., E. P. Cato, and W. E. C. Moore (ed.) 1977. Anaerobe laboratory manual, 4th ed. Anaerobe Laboratory, Virginia Polytechnic Institute and State University, Blacksburg.

15. Holdeman, L. V., and W. E. C. Moore. 1974. New genus, Coprococcus, twelve new species, and emended descriptions of four previously described species of bacteria from human feces. Int. J. Syst. Bacteriol. 24:260-277.

16. Hucker, G. J. 1948. Genus II. Gaffkya Trevisan, p. 283 284. In R. S. Breed, E. G. D. Murray, and A. P. Hitchens (ed.), Bergey's manual of determinative bacteriology, 6th ed. The Williams \& Wilkins Co., Baltimore.

17. Huss, V., K. H. Schleifer, E. Lindal, O. Schwan, and C. J. Smyty. 1982. Peptidoglycan type, base composition of DNA, and DNA-DNA homology of Peptococcus indolicus and Peptococcus asaccharolyticus. FEMS Microbiol. Lett. 15:285-289.

18. Judicial Commission of the International Committee on Systematic Bacteriology. 1971. Opinion 39. Rejection of the generic name Gaffkya Tevisan. Int. J. Syst. Bacteriol. 21:104-105.

19. Judicial Commission of the International Committee on Systematic Bacteriology. 1982. Opinion 56. Rejection of the species name Peptococcus anaerobius (Hamm) Douglas 1957. Int. J. Syst. Bacteriol. 32:468.

20. Kelly, R. B., N. R. Cozzarelli, M. P. Murray, P. Deutscher, I. R. Lehman, and A. Kornberg. 1970. Enzymatic synthesis of deoxyribonucleic acid by polymerase at a single strand break. J. Biol. Chem. 245:39-45.

21. Kilpper, R., U. Buhl, and K. H. Schleifer. 1980. Nucleic acid homology studies between Peptococcus saccharolvticus and various anaerobic and facultative gram-positive cocci. FEMS Microbiol. Lett. 8:205-210.

22. Kilpper-Bälz, R., and K. H. Schleifer. 1981. DNA-rRNA hybridization studies among staphylococci and some other gram-positive bacteria. FEMS Microbiol. Lett. 10:357362

23. Kilpper-Bälz, R., and K. H. Schleifer. 1981. Transfer of Peptococcus saccharolyticus Foubert and Douglas to the 
genus Staphylococcus: Staphylococcus saccharolyticus (Foubert and Douglas) comb. nov. Zentralbl. Bakteriol. Parasitenkd. Infektionskr. Hyg. Abt. 1 Orig. Reihe C 2:324-331.

24. Kluyver, A. J., and C. B. van Niel. 1936. Prospects for a natural system of classification. Zentralbl. Bakteriol. Parasitenkd. Infektionskr. Hyg. Abt. 2 94:369-403.

25. Lambert, M. A. S., and A. Y. Armfield. 1979. Differentiation of Peptococcus and Peptostreptococcus by gas-liquid chromatography of cellular fatty acids and metabolic products. J. Clin. Microbiol. 10:464-476.

26. Ludwig, W., K. H. Schleifer, G. E. Fox, E. Sewaldt, and E. Stackebrandt. 1981. A phylogenetic analysis of staphylococci, Peptococcus saccharolyticus and Micrococcus mucilaginosus. J. Gen. Microbiol. 125:357-366.

27. Mandel, M., L. Igambi, J. Bergendahl, M. L. Dodson, and E. Sheltgen. 1970. Correlation of melting temperature and cesium chloride buoyant density of bacterial deoxyribonucleic acid. J. Bacteriol. 101:333-338.

28. Marmur, J. 1961. A procedure for the isolation of deoxyribonucleic acid from microorganisms. J. Mol. Biol. 3:208218.

29. Moss, C. W., and S. B. Dees. 1975. Identification of microorganisms by gas liquid chromatographic-mass spectrometric analysis of cellular fatty acids. J. Chromatogr. 112:595-604.

30. Porschen, R. K., and E. H. Spaulding. 1974. Phosphatase activity of anaerobic organisms. Appl. Microbiol. 27:744747.

31. Rogosa, M. 1971. Peptococcaceae, a new family to in- clude the gram-positive anaerobic cocci of the genera Peptococcus, Peptostreptococcus, and Ruminococcus. Int. J. Syst. Bacteriol. 21:234-237.

32. Rogosa, M. 1974. Peptococcus Kluyver and van Niel 1936, p. 518-522. In R. E. Buchanan and N. E. Gibbons (ed.), Bergey's manual of determinative bacteriology, 8 th ed. The Williams \& Wilkins Co., Baltimore.

33. Romond, C., R. Sartory, and J. Maigras. 1966. Le coefficient de Shapiro-Chargoff des streptocoques anaérobies. Ann. Inst. Pasteur Paris 111:710-718.

34. Rosenblatt, J. E. 1980. Anaerobic cocci, p. 426-430. In E. H. Lennette, A. Balows, W. J. Hausler, and J. P. Truant (ed.), Manual of clinical microbiology, 3rd ed. American Society for Microbiology, Washington, D.C.

35. Schleifer, K. M., and E. Nimmerman. 1973. Peptidoglycan types of strains of the genus Peptococcus. Arch. Microbiol. 93:245-258.

36. Skerman, V. B. D., V. McGowan, and P. H. A. Sneath (ed.). 1980. Approved lists of bacterial names. Int. J. Syst. Bacteriol. 30:225-420.

37. Smith, L. D. S. 1957. Genus V, Peptostreptococcus Kluyver and van Niel 1936, p. 533-541. In R. S. Breed, E. G. D. Murray, and N. R. Smith (ed.), Bergey's manual of determinative bacteriology, 7 th ed. The Williams \& Wilkins Co., Baltimore.

38. Wilkins, T. D., W. E. C. Moore, S. E. H. West, and L. V. Holdeman. 1975. Peptococcus niger (Hall) Kluyver and van Niel 1936: emendation of description and designation of neotype strain. Int. J. Syst. Bacteriol. 25:47-49. 